\title{
Simultaneous Removal of Cadmium and Copper from a Binary Solution by Cathodic Deposition Using a Spiral-Wound Woven Wire Meshes Packed Bed Rotating Cylinder Electrode
}

\author{
Fouad A.A. Al-Saady ${ }^{1}$ and Ali H. Abbar ${ }^{2 *}$ \\ ${ }^{1}$ Faculty of pharmacy, Al-Mustansriyah University, Iraq \\ ${ }^{2}$ Chemical Engineering Department, University of Al-Qadisiyah, Iraq
}

\begin{abstract}
Spiral-wound woven wire meshes packed bed rotating cylinder electrode was used for the simultaneous removal of cadmium $(\mathrm{Cd})$ and copper $(\mathrm{Cu})$ from a binary solution. The effects of weight percent of each metal on the removal and current efficiencies were studied at an operating current of 345A, while the effect of current on the removal efficiency of both metals was investigated at three levels of current $(240,345$.and $400 \mathrm{~mA})$. The experiments were carried out at constant rotation speed $800 \mathrm{rpm}, \mathrm{pH}=3$, and a total concentration of metals $(500 \mathrm{ppm})$. The results showed that the removal efficiency of copper increased from $89 \%$ to $99.4 \%$ as its weight percent increased from $20 \%$ to $100 \%$. In a similar fashion, the removal efficiency of cadmium increased from $81 \%$ to $97 \%$ as its weight percent increased from $20 \%$ to $100 \%$. The results confirmed that the removal efficiency of any metals declined in the presence of the other. Increasing of current resulted in increasing the removal efficiency of both metals at different weight percents. The results confirmed that current efficiencies for removing of copper and cadmium simultaneously decline with increasing of electrolysis time and weight percent of cadmium or with decreasing the weight percent of copper. Current efficiency was higher at the initial stage of electrolysis for all weight percents of metals. The results showed that the decay of copper concentration was exponential at all weight percents of copper, confirming that the electrodeposition of copper is under mass transfer control in the presence of cadmium. While the decay of cadmium concentration was linear at lower weight percent of cadmium then changed to an exponential behavior at high weight percent of cadmium in the presence of copper.
\end{abstract}

Keywords : Copper, Cadmium, Three-Dimensional Electrodes, Rotating Cylinder Electrode, Spiral-Wound Woven, Electrodeposition.

Received : 18 November 2019, Accepted : 20 August 2020

\section{Introduction}

Metal pollution considers as one of the major environmental problems that face human being where pollution of several water streams by metal ions results from the releasing of heavy metals by industrial plants, chemical synthesis and mining activities. Rapid industrialization has extremely increased the release of such toxic metals to water streams. In comparison with organic pollutants, heavy metals are non-biodegradable and could be accumulated in liv-

*E-mail address: ali.abbar@qu.edu.iq

DOI: https://doi.org/10.33961/jecst.2019.00647

This is an open-access article distributed under the terms of the Creative Commons Attribution Non-Commercial License (http://creativecommons.org/licenses/by-nc/4.0) which permits unrestricted non-commercial use, distribution, and reproduction in any medium, provided the original work is properly cited. ing tissues resulting in numerous disorders and diseases; thus treatment of water streams containing heavy metals is mandatory to remove these hazardous and toxic metals before discharge [1]. Heavy metals such as cadmium and copper are the most common pollutants found in the industrial effluents, which are extremely toxic even at low dosages [2]. Copper is mainly released to water bodies from electroplating, ores processing, mechanical manufacturing industry, light industry and architecture. In spite of existing of copper in the body is essential in a trace amount, using it in high doses results in serious lesions in the central nervous system and even permanent damage especially for children [3]. Cadmium enters into water bodies from cadmium-nickel batteries, smelting, mining, metal plating, pigments, phos- 
phate fertilizers, alloy industries, and sewage sludge. The dangerous effects of cadmium involve many of chronic and acute disorders such as "itai-itai" disease, emphysema, renal destruction, testicular atrophy and hypertension [4]. Hence, removal of cadmium and copper from wastewater is mandatory and their simultaneous removal also offers a costeffective solution because of avoiding the repeated one-by-one removal of pollutants leading to an attractive low-cost strategy [5].

Many traditional treatment methods have been developed to remove cadmium and copper such as reduction and precipitation [6], adsorption on activated carbon [7,8], flotation, coagulation [9], reverse osmosis, ion exchange, and electro-dialysis [10]. Many of them have disadvantages and economic constraints that result in restriction of their application. For example, production of solid sludge in the precipitation method is a serious problem causing challenges in the treatment and landfilling of this solid sludge [11]. Also the high capital and regeneration costs of the materials restricts the large-scale use of activated carbon for metals removal. Therefore, development of a low cost process is required to remove heavy metals economically.

Electrochemical technology as an efficient alternative to the traditional technologies offers electrochemical systems in which the removal of heavy metals from wastewater is performed by electrochemical reduction reactions as a principal approach for removing of these metals from wastewater. These heavy metals are electrodeposited on the electrode surface as solid metallic deposits when the effluents flow through the electrochemical reactor hence the possibility of reusing them from the main process. Herein, adding of chemicals is not required leading to facilitate of water reuse [12-14]. Since the major reaction reagent in the cathodic deposition method is the electron, this method is considered as a clean, environmentally engaging technology [12]. Besides, electrochemical method is valuable due to the lower energy consumption in comparing with the wellknown techniques [13]. Moreover, utilizing the automatization approach in controlling of current during the electrodeposition process make the workload requirements very low [15].

Various electrochemical reactor designs were applied by the researchers in order to removing of copper and cadmium from simulated or real solutions and various degrees of enhancements were achieved [16-23]. For ensuring good performance of the electrochemical method for treating diluted effluents, the electrochemical reactors used in this method should gain higher value of the product of mass-transfer coefficient and specific surface area of the cathode hence improving the space-time yield of these reactors could be obtained. This aim could be achieved via using packed bed rotating cylinder electrodes, which have been recognized as an efficient type of electrochemical reactors that used for removal of heavy metals [24]. This kind of electrochemical reactor has characteristics not engaged by other electrochemical reactors for instance uniform current and potential distributions, the possibility of operating at continuous mode and a simple operable compact design [24,25].

Abbar et al. 2018 [26] investigated the mass transfer properties of a new design of packed bed rotating cylinder electrode called a spiral-wound woven wire mesh rotating cylinder electrode. This configuration consists of a central core or axis (used as a current feeder) around which continuous mesh layers are wrapped. They found that this configuration has a mass-transfer enhancement factor 2.3 times higher than those obtained with smooth rotating cylinder electrodes under the same conditions. In comparison with the other types of packed bed rotating cylinder electrodes [27-31], this design has the benefit of easy assembly and refitting, and it could be scaled up to an industrial level with the same performance. Hence, application of this configuration for removing of heavy metals from wastewaters would be successful and economical. Besides this configuration can be operated at a rotation speed higher than $1000 \mathrm{rpm}$ without vortex formation or incorporating of air bubbles in the solution that occurred in the other designs of packed bed rotating cylinder electrodes [26].

In a further research, Abbar et al. 2019 [32] applied the response surface methodology (RMS) for optimizing the electrochemical removal of cadmium using this configuration of rotating cylinder electrode. Their results showed that the optimum operating conditions for removing of cadmium were a current of $345 \mathrm{~mA}$, rotation speed of $800 \mathrm{rpm}, \mathrm{Cd}$ initial concentration of $500 \mathrm{ppm}, \mathrm{pH}$ of 6.8 , and mesh number of 30 . Under these conditions, cadmium removal efficiency of $98.5 \%$ and current efficiency of $41 \%$ were achieved at $60 \mathrm{~min}$ with specific energy 
consumption of $3.12 \mathrm{kWh} \mathrm{kg}^{-1}$.

To the best of author knowledge, the addition of copper to cadmium and studying its effect on the performance of the spiral-wound woven wire mesh rotating cylinder electrode have not been investigated previously. Therefore, the aim of the present work is to investigate the effect of presence of copper in situ with cadmium on the removal and current efficiencies of the process where the effects of weight percent of each metal on the removal and current efficiencies were investigated.

\section{Experimental}

All runs were achieved in a $0.75 \mathrm{~L}$ undivided jacketed electrochemical cell shown in Fig. 1. A spiralwound woven wire mesh rotating cylinder electrode with an apparent active surface area, $17 \mathrm{~mm}$ diameter and $38 \mathrm{~mm}$ long made from $316 \mathrm{~L}$ stainless steel was used as cathode (working electrode). Its construction and dimensions were described elsewhere [26]. As a counter electrode (anode), Graphite cylinder with dimensions (50 $\mathrm{mm}$ inner diameter and $90 \mathrm{~mm}$ long) was used. The anode and cathode were concentric to ensure uniform primary current distribution. The distance between electrodes was $25 \mathrm{~mm}$. The electrochemical cell temperature was thermostated to $25^{\circ} \mathrm{C}$ $\pm 1^{\circ} \mathrm{C}$ using water bath circulator.

Before starting any run, cathode was washed with (1M) nitric acid solution in an ultrasound cleaner for removing copper and/or cadmium deposits of the previous run then rinsed again thoroughly by doubledistilled water. The galvanostatic mixed metals deposition was conducted by using power Supply-model UNI-T: UTP3315TF-L.

Stainless steel screen having mesh number 30 was used. The properties of this screen are presented in Table 1 . Screen porosity $(\varepsilon)$ was evaluated by determining the screen weight /area density and applying Eq. (1), then screen specific surface area(s) was computed based on Eq.(2) [33]:

$$
\varepsilon=1-\frac{m_{s}}{\rho_{s} l a_{s}}
$$

$$
S=(1-\varepsilon) r
$$

Where (r) is the surface to volume ratio of the screen wire equal to $(4 / \mathrm{d}),\left(\mathrm{m}_{\mathrm{s}} / \mathrm{a}_{\mathrm{s}}\right)$ is the weight /area density, $\left(\rho_{\mathrm{s}}\right)$ is the density of stainless steel 316-AISI equal to $8.027 \mathrm{gm} / \mathrm{cm}^{3}$ [34], $(l)$ is the screen thickness equal to $2 \mathrm{~d}$.

The type of screen woven was identified by using Olympus BX51M with DP70 digital camera system whereas a digital caliper was used to measure wire diameter (d).

Cadmium sulfate $\left(3 \mathrm{CdSO}_{4} .8 \mathrm{H}_{2} \mathrm{O}\right)$ and Copper sulfate $\left(\mathrm{CuSO}_{4}\right)$ were used as a source of copper ion and cadmium ion respectively while sodium sulfate $\left(\mathrm{Na}_{2}\right.$ $\mathrm{SO}_{4)}$ was used as a supporting electrolyte. All chemicals were of reagent grade. Doubly distilled water was used for preparing electrolytic solutions containing copper and cadmium ions dissolved in $0.5 \mathrm{M} \mathrm{Na}_{2}$ $\mathrm{SO}_{4}$ at a total concentration of $500 \mathrm{ppm}$ for different weight percents for these metals $(0,20,40,60,80$, and $100 \%)$. The final $\mathrm{pH}$ of the electrolytic solution was

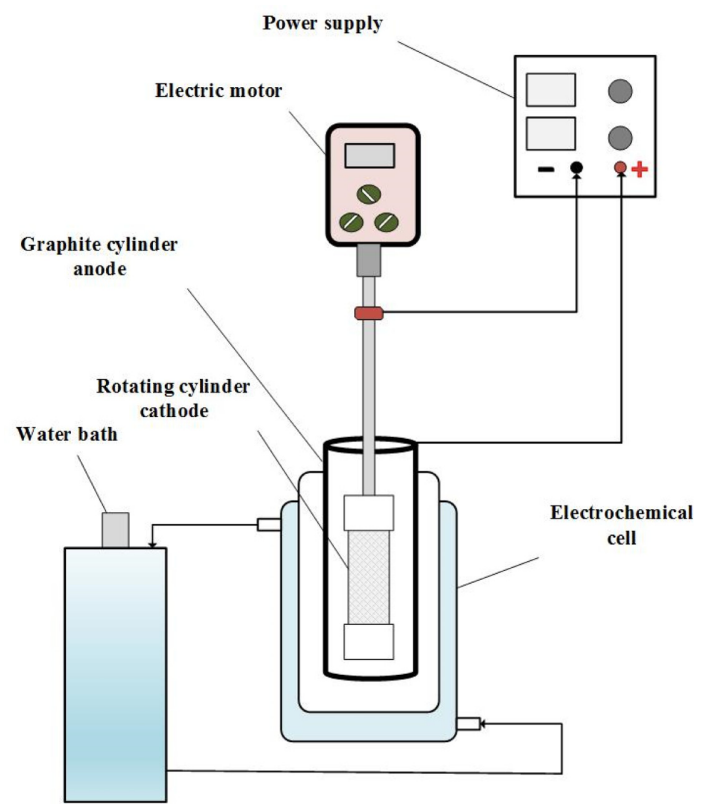

Fig. 1. Schematic diagram of the electrochemical system.

Table 1. Properties of screen with mesh number (30 wire/inch)

\begin{tabular}{cccccc}
\hline \hline Property & Type of woven & $\mathrm{d}, \mathrm{cm}$ & $\left(\mathrm{m}_{\mathrm{s}} / \mathrm{a}_{\mathrm{s}}\right), \mathrm{g} / \mathrm{cm}^{2}$ & $\varepsilon$ & $\mathrm{cm}^{-1} \mathrm{~s}$ \\
\hline Value & Plain square & 0.030 & 0.1237 & 0.7146 & 38.06 \\
\hline
\end{tabular}


adjusted to (3) using (1 M) $\mathrm{H}_{2} \mathrm{SO}_{4}$ or (1M) NaOH. All runs were proceeded at constant temperature of $25 \pm 1^{\circ} \mathrm{C}$ and rotation speed of $800 \mathrm{rpm}$.

The removal efficiency (RE, \%) was computed according to the following equation [23] :

$$
R E=\frac{C_{i}-C_{f}}{C_{i}} \times 100
$$

Where, $C_{i}$ is the initial copper or cadmium concentration, $\mathrm{C}_{\mathrm{f}}$ is the final copper or cadmium concentration after an interval of time $(\Delta t)$.

For mixed metals removal, the current efficiency can be calculated as follows [35]:

$$
\text { CE(\%) of metals }
$$

$$
=\frac{F \times V \times z\left\{\left[\frac{C_{o}-C_{i}}{M}\right]_{C_{u}}+\left[\frac{C_{o}-C_{i}}{M}\right]_{C_{d}}\right\}}{I \times t} \times 100
$$

where F is Faraday's constant; 96,485 coulomb/mole, $\mathrm{z}$ is the number of electrons participating in the reaction, $\mathrm{V}$ is the volume of solution; L, M is the molar mass of heavy metals; $\mathrm{g} / \mathrm{mole}$, I is the applied current; $\mathrm{A}$, and $\mathrm{t}$ is time of electrolysis; $\mathrm{s}$.

\section{Results and discussion}

\subsection{Removal efficiency for binary system}

3.1.1 Effect of weight percent on the removal efficiency

Fig. 2 shows the concentration profiles verses time for cadmium and copper in a binary mixture with composition $(20 \% \mathrm{Cd}, 80 \% \mathrm{Cu})$ under the following operating conditions: current (345 mA), rotation speed $(800 \mathrm{rpm})$, total initial concentration (500 ppm), mesh number (30), and $\mathrm{pH}$ (3). It was observed that the concentration of each heavy metal decreases with increasing of time. At the end of electrochemical removal time (60 $\mathrm{min})$, the final concentration of cadmium and copper were 19 and $10 \mathrm{ppm}$ respectively with final removal efficiencies $81 \%$ and $97.5 \%$ for cadmium and copper respectively. The decay of copper concentration was exponential while that for cadmium was approximately linear.

For a batch, recycle system operated at a galvanostatic mode, two different concentration decays can be observed, a linear decay that correspond to electron transfer control(activated control) and an exponen-

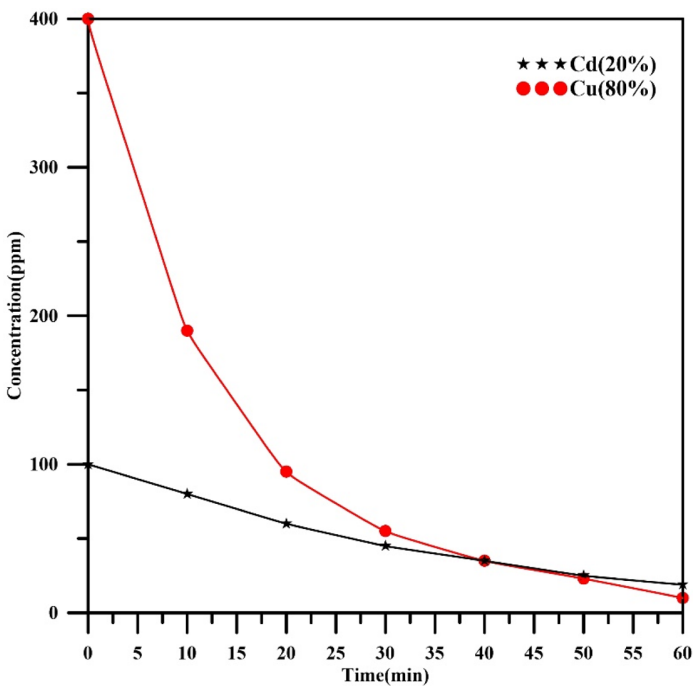

Fig. 2. Concentration profiles verses time for $(20 \% \mathrm{Cd}$, $80 \% \mathrm{Cu}$ ) mixture.

tial decay correspond to a mass transfer control [36]. Under the conditions in which the operating current is less than the limiting current, a zero order kinetics occurs in which the decay of concentration becomes linear. While, at operating current higher than the limiting current, a first order kinetics occurs in which the decay of concentration becomes exponential [37]. Therefore, results of Fig. 2 showed that the electrodeposition of copper at a current of $345 \mathrm{~mA}$ is under mass transfer control while that for cadmium is under activated control. This behavior also confirms that the cathodic potential should be at value more negative than the standard potential of copper $(+0.34 \mathrm{~V}$ vs. SHE) during the electrolysis. Reade et al. [38] observed the same behavior in their work for simultaneous removal of cadmium and copper from a binary solution with pH 2 containing 0.50 moldm $^{-3} \mathrm{Na}_{2} \mathrm{SO}_{4}$ at $298 \mathrm{~K}$ using reticulated vitreous carbon (RVC) as a rotating cylinder electrode. The rates of concentration decay of each metal in Reade et al. [38] work were the same due to the low concentrations of each metals (56ppm $\mathrm{Cd}$ and $32 \mathrm{ppm} \mathrm{Cu}$ ) while in the present work, there is a clear difference between the decay rates of each metal (an exponential decay with respect of copper and a linear decay with respect of cadmium). Similar trends were also observed by Alebrahim et al. [35] in their work for removing of copper and zinc from a binary solution with a total 


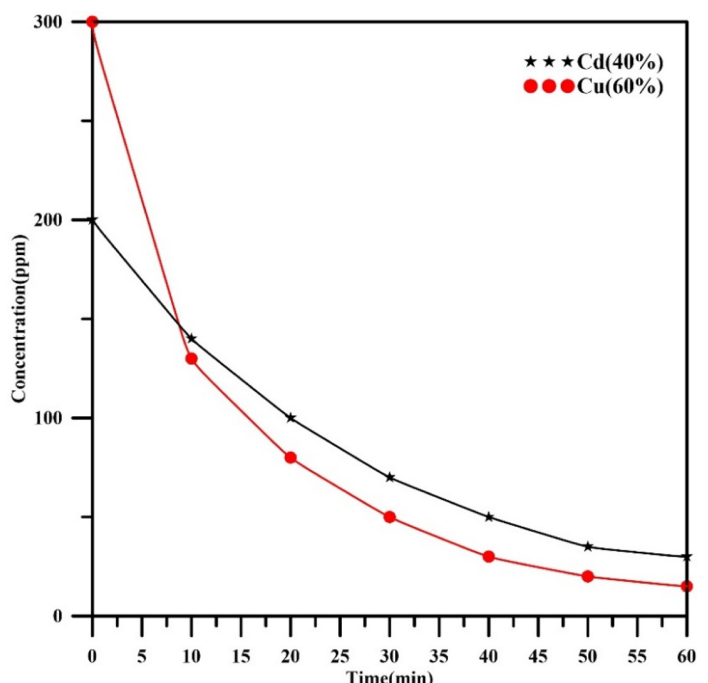

Fig. 3. Concentration profiles verses time for $(40 \% \mathrm{Cd}$ $60 \% \mathrm{Cu}$ ) mixture.

concentration of $500 \mathrm{ppm}$.

Fig. 3 displays the concentration profiles verses time for cadmium and copper in a binary mixture with composition $(40 \% \mathrm{Cd}, 60 \% \mathrm{Cu})$ under the operating current of $345 \mathrm{~mA}$. It can be noted that the concentration of each heavy metal declined with increasing of time. The final concentration of cadmium and copper at 60 minutes were 30 and $15 \mathrm{ppm}$ respectively with final removal efficiencies $85 \%$ and $95 \%$ for cadmium and copper respectively. In comparison with Fig. 2, the decay of copper concentration is still exponential while the decay of cadmium concentration changes during the electrolysis as two regions: in the first region, it is approximately linear up to $20 \mathrm{~min}$ then became exponential at the second region for further time of electrolysis. This behavior also confirms that the value of cathodic potential in this case may be close to the standard potential of cadmium during the electrolyis. Similar observation was found by Khattab, et al. [39] in their work for the simultaneous removal of copper and zinc using a packed-bed cathode composed from carbon particles.

Fig. 4 displays the concentration profiles of each heavy metal $(\mathrm{Cu}, \mathrm{Cd})$ in a binary mixture with composition $(60 \% \mathrm{Cd}, 40 \% \mathrm{Cu})$ verses time under operating current of $345 \mathrm{~mA}$. As can be seen, the concentration of each heavy metal declined with increasing of time. The final value of the cadmium

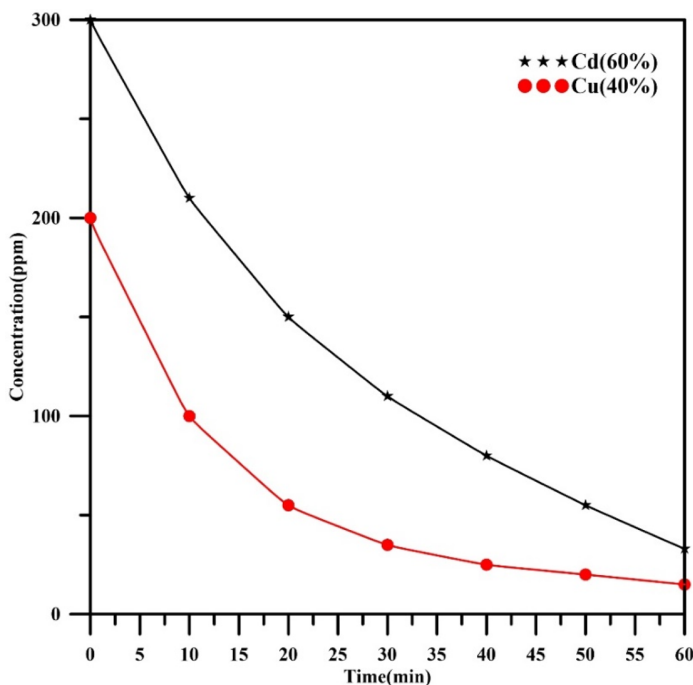

Fig. 4. Concentration profiles verses time for $(60 \% \mathrm{Cd}$, $40 \% \mathrm{Cu}$ ) mixture.

and copper concentrations were 33 and $15 \mathrm{ppm}$ respectively at $60 \mathrm{~min}$ with final removal efficiencies $89 \%$ and $92.5 \%$ for cadmium and copper respectively. In comparison with Fig. 3, the concentration decay of each metal was kept the same approximately with no intersect between them (exponential decay) confirming that electrodeopstion of both metals are under mass transfer control. This behavior also approves that the value of cathodic potential in this case should be more negative than the standard potential of cadmium ( $-0.4 \mathrm{~V}$ vs. SHE). The decay of $\mathrm{Cu}$ concentration is extremely exponential than decay of Cd concentration.

Fig. 5 demonstrates the concentration profiles verses time of each heavy metals $(\mathrm{Cu}, \mathrm{Cd})$ in a binary solution with composition $(80 \% \mathrm{Cd}, 20 \% \mathrm{Cu})$ under operating current of $345 \mathrm{~mA}$. The data showed that the concentration of each heavy metals declined with increasing of time. The final value of concentrations for cadmium and copper were 28 and $11 \mathrm{ppm}$ respectively at 60 min with final removal efficiencies $93 \%$ and $89 \%$ for cadmium and copper respectively. Results indicated that the final concentrations of copper and cadmium became slightly lower in comparison with Fig.4. The concentration decays of both metals were kept the same approximately with no intersect between them (exponential decay), confirming that both metals are deposited under mass transfer control. 


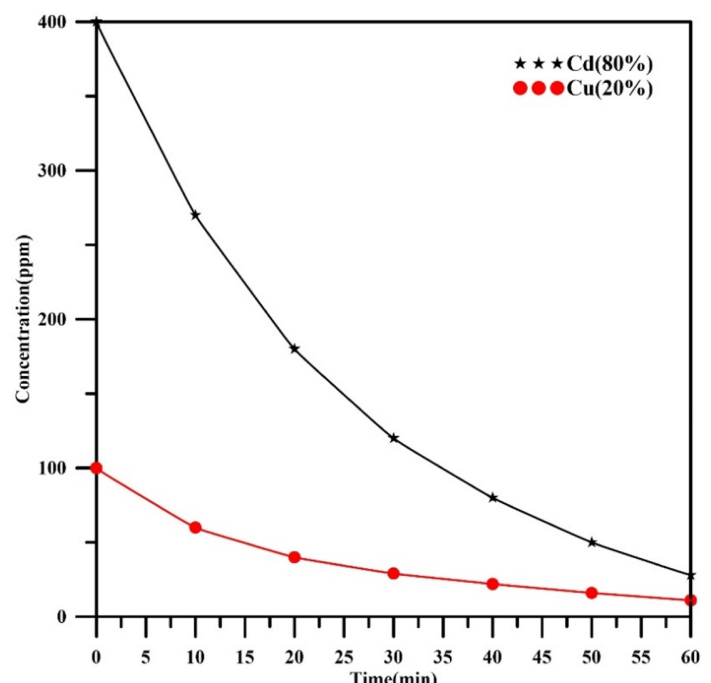

Fig. 5. Concentration profiles verses time for $(80 \% \mathrm{Cd}$, $20 \% \mathrm{Cu}$ ) mixture.

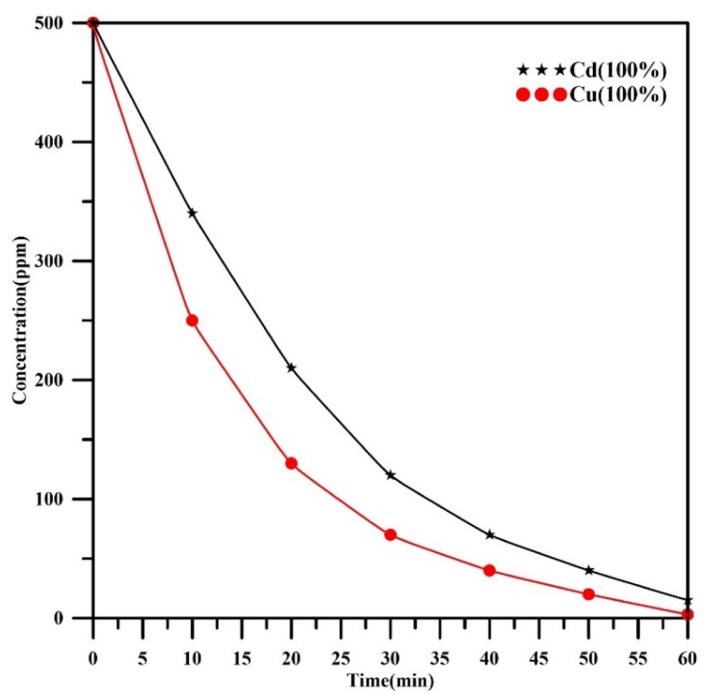

Fig. 6. Concentration profile verses time for single metal.

In order to confirm the impact of copper existing during cadmium removal, two further experiments were achieved on monometallic $\mathrm{Cu}$ and $\mathrm{Cd}$ solutions under the conditions (current $345 \mathrm{~mA}$, rotation speed of $800 \mathrm{rpm}, \mathrm{Cd}$ or $\mathrm{Cu}$ initial concentration $500 \mathrm{ppm}$, mesh number of 30 , and $\mathrm{pH}=3$ ). The results are shown in Fig. 6. The final concentration of copper alone at $60 \mathrm{~min}$ was $3 \mathrm{ppm}$ with a removal efficiency of $99.4 \%$ while the final concentration of cadmium

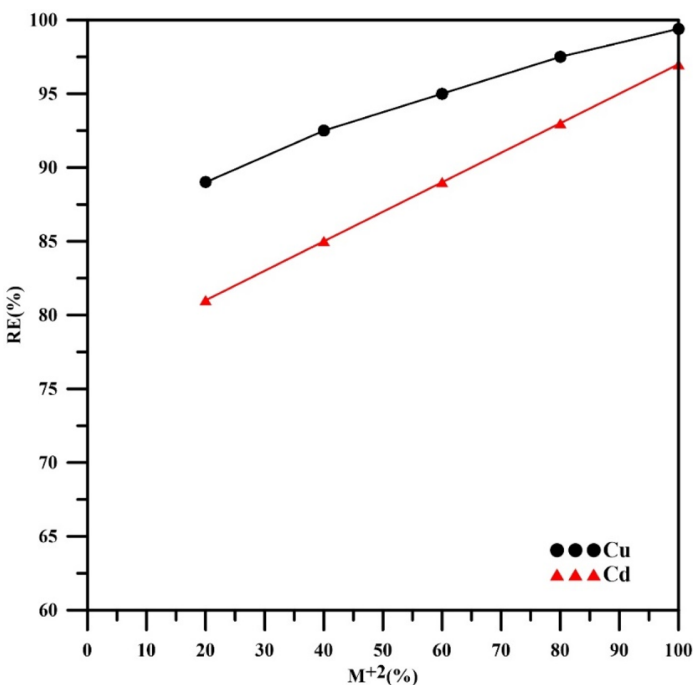

Fig. 7. Removal efficiency verses heavy metal weight percent in the binary system.

alone was $15 \mathrm{ppm}$ at the same time with a removal efficiency of $97 \%$. The removal efficiency in the present work is lower than that reported previously in our previous work [32] due to the decreasing of $\mathrm{pH}$ from 6.8 to 3 . Using $\mathrm{pH}$ higher than 3 in the simultaneous removal of cadmium and copper is not recommended because of the possibility of precipitating of copper as hydroxide if the solution $\mathrm{pH}$ becomes greater than 3 as approved by theoretical solubility of copper hydroxide diagram[40]. The main outcome of the present work is the capability of the spiral-wound woven wire mesh rotating cylinder electrode to remove copper at higher removal efficiency close to $100 \%$.

Fig. 7 shows how the weight percent of heavy metal effects on the removal efficiency of each metal. The results showed that the removal efficiency of copper increased from $89 \%$ to $99.4 \%$ as its weight percent increased from $20 \%$ to $100 \%$. In a similar fashion, the removal efficiency of cadmium increased from $81 \%$ to $97 \%$ as its weight percent increased from $20 \%$ to $100 \%$. The results confirmed that the removal efficiency of any metal decreased in the presence of the other metal. Alebrahim et al. [35] found similar observations in their work for removing of copper and zinc from a simulated binary solution using a packed-bed cathode. However, selective separation of copper was happened in their work due 


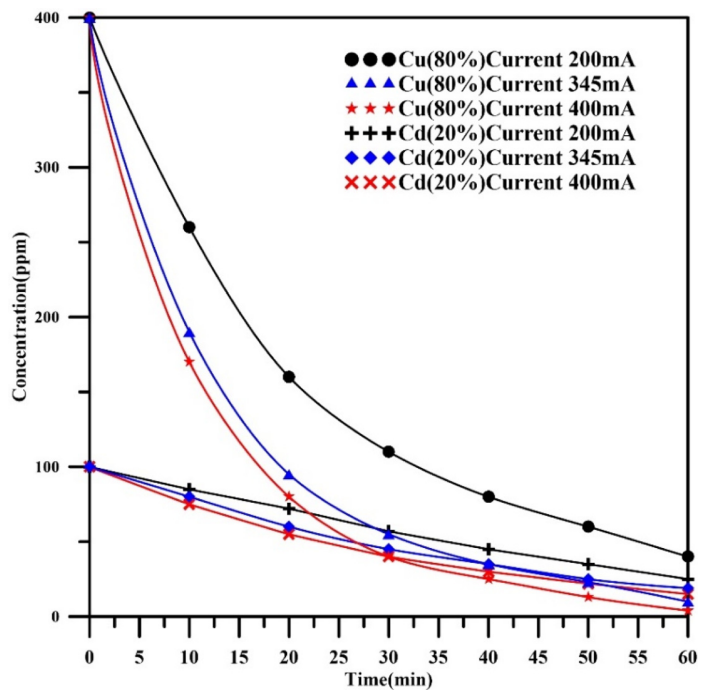

Fig. 8. Concentration profiles verses time for $(80 \% \mathrm{Cu}$, $20 \% \mathrm{Cd}$ ) mixture at different applied currents.

to the large deference in the standard potentials of copper and zinc $\left(\mathrm{E}^{\circ}=+0.34 \mathrm{~V}\right.$ vs. SHE for copper and $\mathrm{E}^{\mathrm{o}}=-0.762 \mathrm{~V}$ vs. SHE for zinc), even though the real values are reliant on the real concentrations of metals. The results indicated that copper was removed faster than cadmium. This behavior was expected since the standard potential of cadmium is more negative than copper $\left(\mathrm{E}^{\mathrm{o}}=+0.34 \mathrm{~V}\right.$ vs. SHE for copper and $\mathrm{E}^{\mathrm{o}}=$ $0.4 \mathrm{~V}$ vs. SHE for cadmium).

It is well known, from electrochemistry principles, that the metal ion which has a standard reduction potential with more positive value can be easily reduced. Similar observation was found by Walsh [41] for potentiostatic removal of copper, cadmium and zinc at initial concentration of $10 \mathrm{ppm}$ for each metal using three dimensional reticulated vitreous carbon (RVC) electrode. In addition, similar trend was observed by Alebrahim et al. [35].

3.1.2 Effect of applied current on the removal efficiency

Fig. 8 depicts the effect of applied current on the concentration profiles verses time for each metal for the case of using a binary solution containing $(\mathrm{Cd}$ $20 \%, \mathrm{Cu} 80 \%$ ). It was observed that increasing current causes reducing the final concentration of each metal. Using a current of $240 \mathrm{~mA}$ gave lower removal efficiency for each metal as shown in Fig. 9.

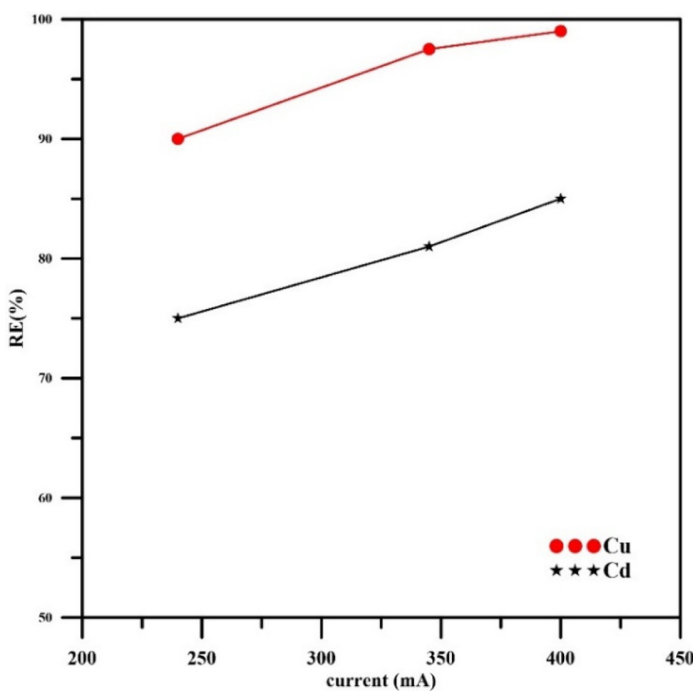

Fig. 9. Effect of current on the removal efficiency for $(80 \% \mathrm{Cu}, 20 \% \mathrm{Cd})$ mixture.

\subsection{Effect of weight percent on the current effi- ciency}

Fig.10 shows that the current efficiency of metal removal decreases with increasing of electrolysis time as well as with increasing of $\mathrm{Cd}$ weight percent or decreasing $\mathrm{Cu}$ weight percent. Current efficiency is always higher at the initial stage of electrolysis and then declines with increasing time for all weight percents of metals. These observations reveal that the main reason for declining of current efficiency is the evolution of hydrogen during the initial periods of electrolysis. However, there are other reasons that may be caused the decline in the current efficiency at the later stages of electrodeposition [35]. The IR drop resulted from passaging the applied electric current through the cell solution is one of reasons that causing the loss in current efficiency. This loss could be seemed when the temperature of electrolysis increased with the progress of electrolysis. In all runs performed at $345 \mathrm{~mA}$. However, the rise in temperature did not exceed $3^{\circ} \mathrm{C}$ at the end of the electrolysis; therefore, the IR drop could not consider as a major factor.

The relation between current efficiency and weight percent of cadmium is shown in Fig. 11, where increasing the weight percent of cadmium results in decreasing the current efficiency since the participation of copper is lowered in addition to the main 


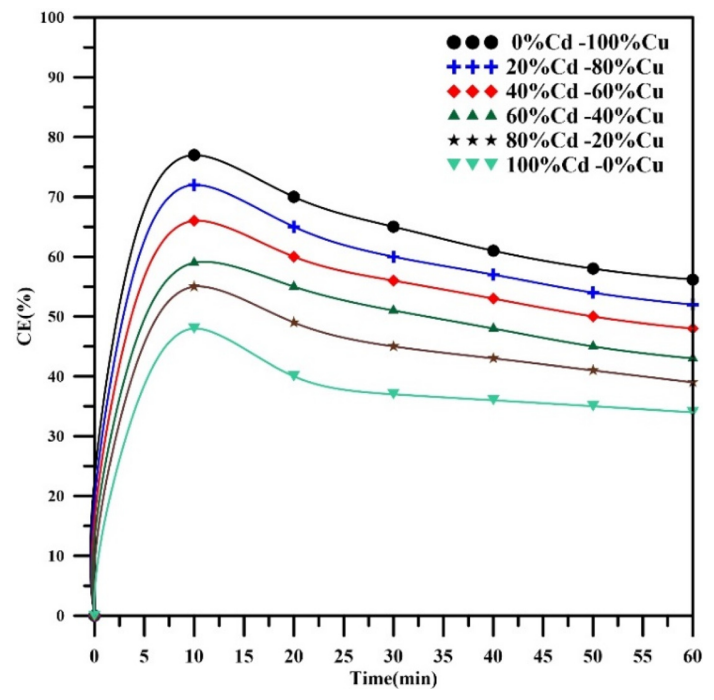

Fig. 10. Current efficiency verse time at different weight percent of Copper and Cadmium.

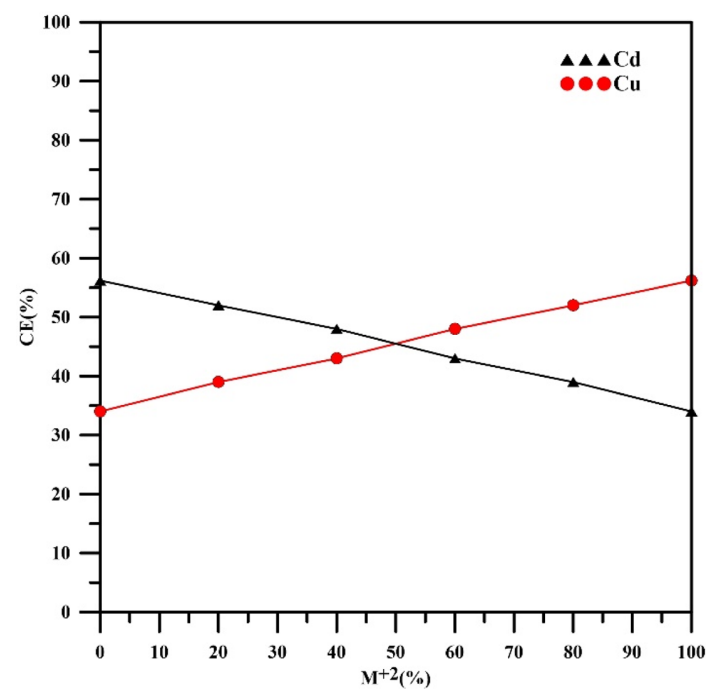

Fig. 11. Effect of weight percent of Copper or cadmium on the Current efficiency.

effect of hydrogen.

The Current efficiency was $52 \%$ at $20 \%$ Cd then decreased to $34 \%$ at $100 \% \mathrm{Cd}$. The current efficiency of copper was increased from $39 \%$ at $20 \% \mathrm{Cu}$ to $56 \%$ at $100 \% \mathrm{Cu}$. Generally, hydrogen evolution considers as the main affected parameter on the current effi- ciency. Alebrahim et al. [35] found similar observations.

\section{Conclusions}

The simultaneous removal of copper and cadmium from a binary solution was achieved successfully using a spiral-wound woven wire mesh rotating cylinder electrode. The results showed that, in the presence of copper, removal efficiency of cadmium decreases with increasing copper weight percent. Similar trend was noted in the case of copper in the presence of cadmium. Increasing the current would improve the removal efficiency of any metal at any weight percent. Based on the results of the present work, it could be removed both metals at a removal efficiency greater than $85 \%$ if they are exist at the same solution with the same weight percent at an applied current of $345 \mathrm{~mA}$ and of course higher removal efficiency can be obtained when the current increases up to $400 \mathrm{~mA}$. The results revealed that current efficiency is higher at the initial stage of electrolysis then declined with the progress of time. Increasing the weight percent of cadmium led to decrease the current efficiency. Opposite behavior was noted in the case of copper. In spite of the low current efficiency due to the effect of side reaction (hydrogen evolution), the process is environmentally benefit since hydrogen can be utilized as a renewable energy.

\section{Acknowledgement}

The authors wish to acknowledge the helpful and technical assistance given by the staff of Faculty of pharmacy, Al-Mustansriyah University.

\section{References}

[1] M. A. Salam, G. Al-Zhrani, S. A. Kosa, C. R. Chimie, 2012, 15(5), 398- 408.

[2] P. X. Sheng, Y. P. Ting, J. P. Chen, L. Hong, J. Colloid Interface Science, 2004, 275(1), 131-141.

[3] B. Yu, Y. Zhang, A. Shukla, S. S. Shukla, K. L. Dorris, J. Hazard. Mater, 2000, 80(1-3), 33-42.

[4] M. Madhava Rao, A. Ramesh, , G. Purna Chandra Rao, K. Seshaiah, Journal of Hazardous Materials, 2006, 129(1-3),123-129.

[5] F. Patrice Fato, D-W. Li, L.-J. Zhao, K. Qiu, Y. Long, ACS Omega, 2019, 4(4), 7543-7549.

[6] O. J. Esalah, M. E. Weber, J. H. Vera, The Can. J. 
Chem. Engg, 2000, 78(5), 948-954.

[7] V. Ravindran, M. R. Stevens, B. N. Badriyha , M. Pirbazari, Am. Inst. of Chem. Engg. J, 1999, 45(5), 11351146.

[8] C. A. Toles, W. E. Marshall, Sep. Sci. and Tech, 2002, 37(10), 2369-2383.

[9] A. I. Zouboulis, K. A. Matis, B. G. Lanara, C. LoosNeskovic, Separation Science and Technology, 1997, 32(10), 1755-1767.

[10] L. Canet, M. Ilpide, P. Seta, Sep. Sci. and Tech, 2002, 37(8), 1851-1860.

[11] H. Eccles, Trends in Biotechnology, 1999, 17(12), 462465.

[12] F. Fu, Q. Wang, J. Environ. Manage, 2011, 92(3), 407418.

[13] K. Juttner, U. Galla, H. Schmieder, Electrochimica Acta, 2000, 45(15-16), 2575-2594.

[14] D. Pletcher, F. C. Walsh, Industrial Electrochemistry, Chapman and Hall, New York, 1990.

[15] G. A. Tonini, F. R. Martins, P. F. De Almeida PradoMartins, L. A., Ruotolo , J. Chem. Technol. Biotechnol, 2013, 88(5), 800-807.

[16] A. Yaqub, H. Ajab, S. Khan, S. Khan, R. Farooq, Water Quality Research Journal, 2009, 44(2), 183-188.

[17] S. H. Chang, K. S. Wang, P. I. Hu, I. C. Lui, Journal of hazardous materials, 2009, 163(2-3), 544-549.

[18] S. Chellammal, S. Raghu, P. Kalaiselvi, G. Subramanian, Journal of hazardous materials, 2010, 180(1-3), 91-97.

[19] C. A. Basha, R. Saravanathamizhan, V. Nandakumar, K. Chitra, C. W. Lee, Chemical Engineering Research and Design, 2013, 91(3), 552-559.

[20] I. A. Khattab, M. F. Shaffei, N. A. Shaaban, H. S. Hussein, S. S. Abd El-Rehim, Egyptian Journal of Petroleum , 2013, 22(1), 199-203.

[21] I. A. Khattab, M. F. Shaffei, N. A. Shaaban, H. S. Hussein, S. S. Abd El-Rehim, Egyptian Journal of Petroleum, 2013, 22(1), 205-210.

[22] Ma. L. Llovera-Hernandez, A. Alvarez Gallegos, J.A. Hernandez, S. Silva-Martinez, Desalination Water Treat, 2016, 57(48-49), 22809-22817.

[23] A. H. Sulaymon, S. A. M. Mohammed, A. H. Abbar, Desalination Water Treat, 2017, 74, 197-206.
[24] F. C. Walsh, Electrochemistry for a cleaner environment, USA, 1992

[25] D. R. Gabe, J. Appl. Electrochem, 1974, 4(2), 91-108.

[26] A. H. Abbar, R. H. Salman, A. S. Abbas, Chemical Engineering \& Processing: Process Intensification, 2018, 127, 10-16.

[27] J. M. Grau, J. M. Bisang, J. Chem. Technol. Biotechnol, 2001, 76(2), 161-168.

[28] J. M. Grau, J. M. Bisang, J. Chem. Technol. Biotechnol, 2003, 78(10), 1032-1037.

[29] G. W. Reade, P. Bond, C. P. de Leon, F. C. Walsh, J. Chem. Techno.l Biotechnol, 2004, 79(9), 946-953.

[30] J. M. Grau, J. M. Bisang, J. Appl. Electrochem, 2007, 37(2), 275-282.

[31] J. M. Grau, J. M. Bisang, J. Chem. Technol. Biotechnol, 2009, 84(7), 1084-1089.

[32] A. H. Abbar, R. H. Salman, A. S. Abbas, Environmental Technology \& Innovation, 2019, 13, 233-243.

[33] R. E. Sioda, J. Electroanalytical. Chem. and Interfacial Electrochem., 1976, 70(1), 49-54.

[34] D. Green, R. Perry, Perry's Chemical Engineers' Handbook, $8^{\text {thed }}$. McGraw-Hill, New York, 2008

[35] M. F. Alebrahim, I. A. Khattab, Q. Cai, M. Sanduk, Egyptian journal of petroleum, 2017, 26(2), 225-234.

[36] A. T. S. Walker, A. A. Wragg, Electrochim. Acta, 1977, 22(10), 1129-1134.

[37] V. D. Stankovic, A. A. Wragg, J. Appl. Electrochem, 1995, 25(6), 565-573

[38] G. W. Reade, A. H. Nahle, P. Bond, J. M. Friedrich, F. C. Walsh, Journal of Chemical Technology \& Biotechnology: International Research in Process, Environmental \& Clean Technology, 2004, 79(9), 935945.

[39] I. A. Khattab, M. F. Alebrahim, M. Sanduk, Research Journal of Pharmaceutical Biological and Chemical Sciences, 2017, 8(3), 273-282.

[40] D.M. Ayres, A. P. Davis, P.M. Gietka, Removing Heavy Metals from Wastewater, Engineering Research Centre Report, 1994, 90.

[41] F. C. Walsh, Pure and applied chemistry, 2001, 73(12), 1819-1837. 